\title{
Kallikrein-Modified Mesenchymal Stem Cell Implantation Provides Enhanced Protection Against Acute Ischemic Kidney Injury by Inhibiting Apoptosis and Inflammation
}

\author{
Makoto Hagiwara, Bo Shen, Lee Chao, and Julie Chao
}

\begin{abstract}
Mesenchymal stem cells (MSCs) migrate to sites of tissue injury and serve as an ideal vehicle for cellular gene transfer. As tissue kallikrein has pleiotropic effects in protection against oxidative organ damage, we investigated the potential of kallikrein-modified MSCs (TK-MSCs) in healing injured kidney after acute ischemia/reperfusion (I/R). TK-MSCs secreted recombinant human kallikrein with elevated vascular endothelial growth factor levels in culture medium, and were more resistant to oxidative stress-induced apoptosis than control MSCs. Expression of human kallikrein was identified in rat glomeruli after I/R injury and systemic TK-MSC injection. Engrafted TK-MSCs exhibited advanced protection against renal injury by reducing blood urea nitrogen, serum creatinine levels, and tubular injury. Six hours after I/R, TK-MSC implantation significantly reduced renal cell apoptosis in association with decreased inducible nitric oxide synthase expression and nitric oxide levels. Forty-eight hours after I/R, TK-MSCs inhibited interstitial neutrophil and monocyte/macrophage infiltration and decreased myeloperoxidase activity, superoxide formation, p38 mitogen-activated protein kinase phosphorylation, and expression of tumor necrosis factor- $\alpha$, monocyte chemoattractant protein-1, and intercellular adhesion molecule-1. In addition, tissue kallikrein and kinin significantly inhibited $\mathrm{H}_{2} \mathrm{O}_{2}$-induced apoptosis and increased Akt phosphorylation and cell viability in cultured proximal tubular cells. These results indicate that implantation of kallikrein-modified MSCs in the kidney provides advanced benefits in protection against ischemia-induced kidney injury by suppression of apoptosis and inflammation.
\end{abstract}

\section{Introduction}

A CUTE RENAL FAILURE (ARF) is a common disease with high morbidity and mortality. In renal transplant populations, an early ischemic insult is believed to cause longterm renal dysfunction (Chertow et al., 2005; Hertig et al., 2006). Unfortunately, innovative interventions beyond supportive therapy are currently not available. Mesenchymal stem cells (MSCs) serve as an ideal vehicle for cellular gene transfer because they are nonimmunogenic and immunosuppressive, and have the ability to migrate to sites of tissue injury and inflammation to participate in tissue repair (Yokoo et al., 2003). Studies have shown that implantation of bone marrow-derived MSCs after renal ischemia/reperfusion (I/R) promoted recovery of renal function and morphological damage, indicating potential promise of healing damaged kidney after acute I/R injury with MSCs (Lange et al., 2005; Togel et al., 2005). Moreover, MSCs genetically modified with the antiapoptotic Akt gene or the antioxidant enzyme heme oxygenase (HO)-1 gene were more efficient in improving cardiac performance and healing damaged myocardium compared with unmodified MSCs by enhancing stem cell viability via autocrine and paracrine actions (Mangi et al., 2003; Tang et al., 2005). In addition to the migrating and homing ability of MSCs (Herrera et al., 2007), the paracrine effects of MSCs have been attracting a great deal of attention as the main mechanism of beneficial effects (Togel et al., 2005). These experimental results indicate that enhanced stem cell therapy by genetic modification provides advanced benefits in protection against ischemic injury.

Tissue kallikrein is a serine proteinase that processes kininogen substrates to release vasoactive kinin peptides. Using a somatic gene transfer approach, we previously demonstrated that tissue kallikrein exhibits renal protection by antiinflammatory and antifibrotic actions in several animal models of renal injury (Chao et al., 1998; Murakami et al., 1998; Bledsoe et al., 2006). Furthermore, we reported that kallikrein reduced ischemia-induced cardiomyocyte apoptosis via Akt-mediated signaling pathways (Yin et al., 2005). Tissue kallikrein gene delivery exhibits pleiotropic effects in

Department of Biochemistry and Molecular Biology, Medical University of South Carolina, Charleston, SC 29425. 
protection against oxidative damage in the heart, kidney, and brain (Xia et al., 2004; Zhang et al., 2004; Li et al., 2007). Our present study was designed to test the hypothesis that mesenchymal stem cells genetically modified with the kallikrein gene exert advanced beneficial effects in protection against acute renal I/R injury by suppression of apoptosis and inflammation.

\section{Materials and Methods}

\section{Mesenchymal stem cell isolation}

Bone marrow (BM) was obtained from 2-month-old male Wistar rats (Deng et al., 2003). Briefly, rats were killed, and femurs and tibias were aseptically removed. BM was flushed from the shaft of the bone with Dulbecco's modified Eagle's medium (DMEM; Sigma-Aldrich, St. Louis, MO) containing $5 \%$ fetal calf serum (FCS; Invitrogen, Paisley, UK) plus penicillin $(100 \mathrm{U} / \mathrm{ml})$-streptomycin $(0.1 \mathrm{mg} / \mathrm{ml})$ (Invitrogen), and then filtered through a $100-\mu \mathrm{m}$ (pore size) sterile filter (Falcon; BD Biosciences, San Jose, CA) to produce a singlecell suspension. MSCs were recovered from BM by their tendency to adhere tightly to plastic culture dishes. Filtered BM cells were plated in DMEM plus 10\% FCS and penicillin (100 $\mathrm{U} / \mathrm{ml})$-streptomycin $(0.1 \mathrm{mg} / \mathrm{ml})$ and allowed to adhere. MSCs were identified by positive immunostaining for vimentin and $\alpha$-smooth muscle actin ( $\alpha$-SMA) in passage 2 as described previously (Davani et al., 2003). Briefly, cells were washed once and fixed with $3.7 \%(\mathrm{v} / \mathrm{v})$ formaldehyde in phosphate-buffered saline (PBS). MSCs were incubated with the primary antibodies anti- $\alpha$-SMA (Dako, Glostrup, Denmark) and anti-vimentin (Santa Cruz Biotechnology, Santa Cruz, CA) overnight at $4^{\circ} \mathrm{C}$, and then with fluorescein-conjugated secondary antibody for $1 \mathrm{hr}$ at room temperature. Immunostaining was examined with a fluorescence microscope.

\section{Generation of genetically modified MSCs expressing human tissue kallikrein}

Ad.CMV-GFP (adenovirus harboring the green fluorescent protein [GFP]-encoding gene) and Ad.CMV-TK (adenovirus carrying human tissue kallikrein cDNA) were generated as previously described (Chao et al., 1998). Cultured MSCs were transduced with Ad.CMV-TK (TK-MSCs) and Ad.CMV-GFP (GFP-MSCs) at a multiplicity of infection (MOI) of 50 for $2 \mathrm{hr}$, followed by a second transduction with adenovirus at an MOI of 100 for $24 \mathrm{hr}$. To determine the transduction efficiency, the ratio of GFP-expressing cells to total cells was calculated with a fluorescence microscope. Expression of recombinant human tissue kallikrein in MSCs was identified by immunostaining and by measuring immunoreactive human tissue kallikrein levels secreted into the culture medium, using a specific enzyme-linked immunosorbent assay (ELISA) (Chao et al., 1998). Vascular endothelial growth factor (VEGF) levels in the culture medium of MSCs 4 days after transduction were measured with an ELISA kit (R\&D Systems, Minneapolis, MN) according to the manufacturer's instructions.

\section{Detection of apoptosis caused by $\mathrm{H}_{2} \mathrm{O}_{2}$ or hypoxia}

GFP-MSCs and TK-MSCs were seeded in 6-well plates. At $70 \%$ confluency, cells were treated with $\mathrm{H}_{2} \mathrm{O}_{2}(0.5 \mathrm{mM})$ for
$6 \mathrm{hr}$ as previously described (Lim et al., 2006). MSCs were then incubated with Hoechst $33342(1 \mu \mathrm{g} / \mathrm{ml})$ for $10 \mathrm{~min}$ in the dark. Apoptotic cells were identified by their distinct condensed nuclei. Caspase-3 activity in cell lysates was determined with a fluorometric caspase-3 assay kit (Oncogene, San Diego, CA) according to the manufacturer's instructions.

\section{Animal treatment}

Male Wistar rats (Harlan, Indianapolis, IN) were housed at a constant room temperature with a $12 \mathrm{hr}: 12 \mathrm{hr}$ light:dark cycle and had free access to tap water and rat chow. All procedures complied with the standards for care and use of animal subjects as stated in the Guide for the Care and Use of Laboratory Animals (Institute of Laboratory Resources, National Academy of Sciences, Bethesda, MD). Rats were anesthetized and subjected to renal ischemia/reperfusion (I/R) injury as previously described (Togel et al., 2005). Briefly, after abdominal laparotomy, kidneys were exposed and renal pedicles were clamped with vascular clamps for $40 \mathrm{~min}$ to induce ischemia. After reflow, the left carotid artery was cannulated with PE50 tubing. MSCs expressing GFP or TK $\left(1 \times 10^{6}\right)$ in $200 \mu \mathrm{l}$ were injected via the carotid artery within $1 \mathrm{hr}$. The same amount of PBS was infused into the control I/ R group by the same route. Thus, rats with $I / R$ were randomly divided into three groups: I/R plus PBS (I/R, $n=16)$, I/R plus GFP-MSCs (I/R + GFP-MSCs, $n=16$ ), and I/R plus TKMSCs (I/R + TK-MSCs, $n=16)$. Sham-operated control animals (sham, $n=12$ ) did not undergo occlusion of the renal arteries. At 6 and $48 \mathrm{hr}$ after I/R, rats were anesthetized and blood samples were taken from the right atrium. Blood urea nitrogen (BUN) and serum creatinine levels were measured with commercial kits (BioAssay Systems, Hayward, CA). Kidneys were removed and snap frozen in liquid nitrogen or fixed in formaldehyde for immunohistochemical studies.

\section{Morphological and histological analyses}

Kidneys were fixed in $4 \%$ formaldehyde, dehydrated, and paraffin embedded. Sections ( $4 \mu \mathrm{m}$ thick) were stained with periodic acid-Schiff (PAS) or hematoxylin and eosin (H\&E). Kidney sections were examined in a blinded manner and scored to evaluate the degree of tubular necrosis (Haq et al., 1998). The scoring method was as follows: 0 , normal kidney; 1 , minimal necrosis ( $<5 \%$ involvement); 2 , mild necrosis ( 5 to $<25 \%$ involvement); 3 , moderate necrosis ( 25 to $<75 \%$ involvement); 4 , severe necrosis ( $>75 \%$ involvement). Neutrophil infiltration into the interstitium was determined by counting neutrophils in 10 randomly selected fields at $\times 400$ magnification in the outer stripe of the medulla, the area of maximal neutrophil migration as described previously (Haq et al., 1998).

\section{Measurement of nitrate/nitrite, myeloperoxidase activity, and superoxide formation}

Renal tissue was homogenized in lysis buffer $(10 \mathrm{mM}$ Tris [pH 7.4], $100 \mathrm{mM} \mathrm{NaCl}, 1 \mathrm{mM}$ EDTA, $20 \mathrm{mM} \mathrm{Na}{ }_{4} \mathrm{P}_{2} \mathrm{O}_{7}, 2 \mathrm{mM}$ $\mathrm{Na}_{3} \mathrm{VO}_{4}$, and $1 \%$ Triton X-100) containing 1:100 protease inhibitor cocktail (Sigma-Aldrich). Nitrate/nitrite (NOx) levels (indicative of NO formation) were measured by a fluorometric assay (Chao et al., 2007). Myeloperoxidase activity was determined as previously described (Suzuki et al., 1983). Super- 

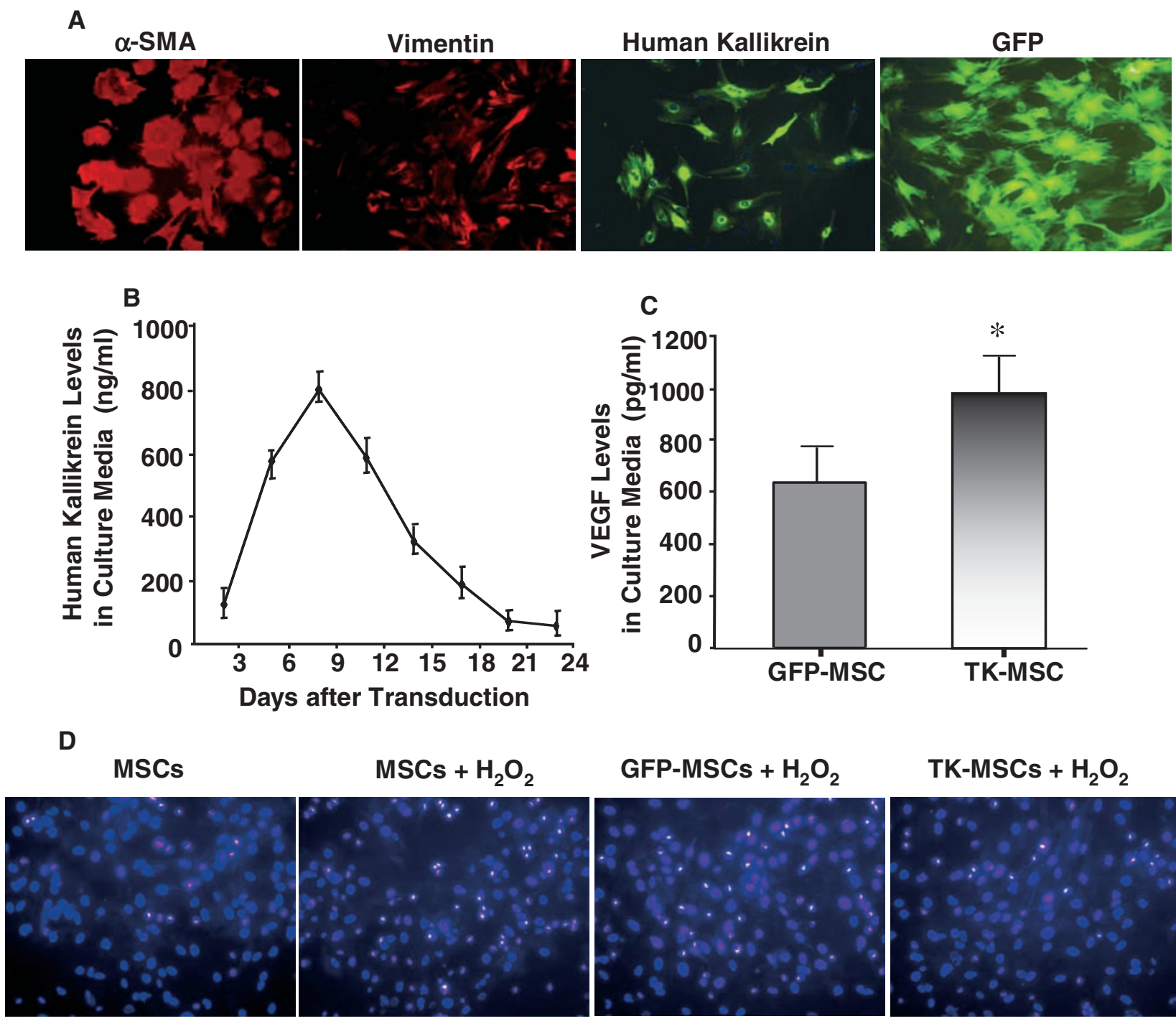

TK-MSCs $+\mathrm{H}_{2} \mathrm{O}_{2}$

E

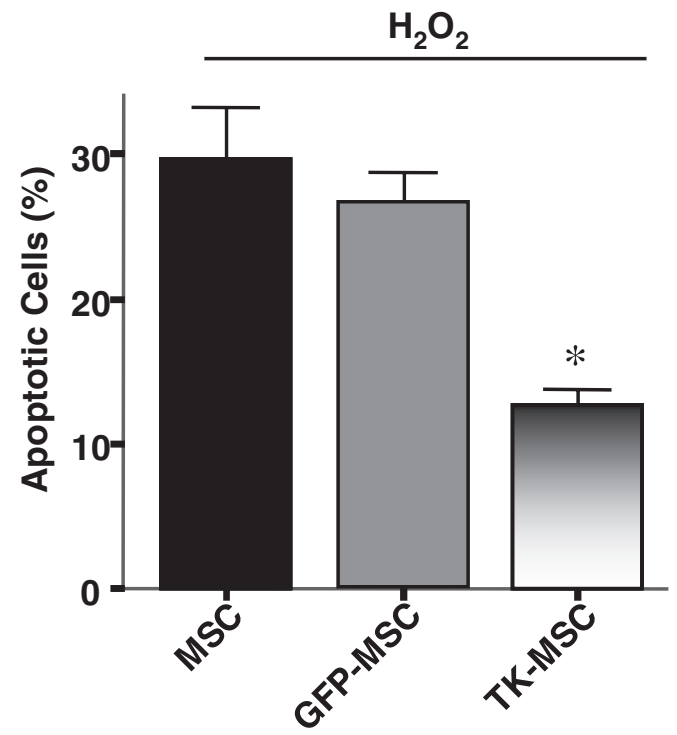

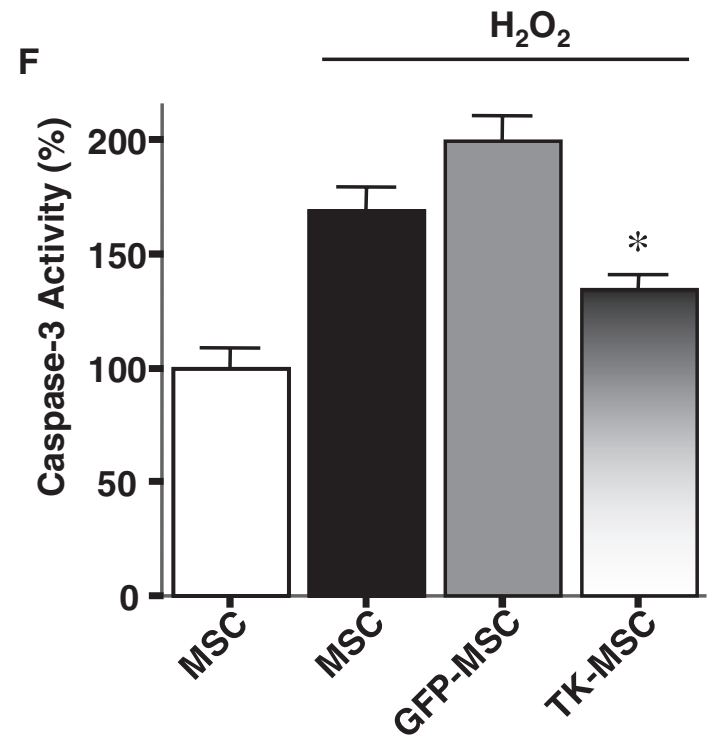

FIG. 1. Immunocytochemical characterization of MSCs and ROS-induced apoptosis. (A) TK-MSCs were identified by positive immunostaining to human tissue kallikrein, $\alpha$-SMA, and vimentin. A transduction efficiency of $70-80 \%$ was confirmed by GFP expression. (B) Expression of human tissue kallikrein in TK-MSC culture medium was determined by ELISA $(n=$ 6-8). (C) Expression of VEGF in TK-MSCs culture medium 4 days after Ad.CMV-TK transduction $\left(n=4,{ }^{*} p<0.05\right.$ vs. GFPMSCs). (D) Representative Hoechst staining images of MSCs treated with $\mathrm{H}_{2} \mathrm{O}_{2}$ for $6 \mathrm{hr}$. (E) Quantitative analysis of apoptotic MSCs expressed as a percentage of total cell number. (F) Caspase-3 activity in cell lysates of MSCs treated with $\mathrm{H}_{2} \mathrm{O}_{2}$ for $6 \mathrm{hr}$. Caspase-3 activity is expressed as a percentage of control MSCs $\left(n=6,{ }^{*} p<0.05\right.$ vs. MSCs and GFP-MSCs). Values are expressed as means \pm SEM. 
oxide production in renal extracts was quantified by a spectrophotometric assay based on rapid reduction of ferricytochrome $c$ to ferrocytochrome $c$ according to a modified protocol (Griendling et al., 1994). Reduction of ferricytochrome $c$ independent of superoxide was corrected for by deducting the activity not inhibited by superoxide dismutase.

\section{Immunohistochemical staining and quantitative analysis}

Immunohistochemistry was performed with a VECTASTAIN Universal Elite ABC kit (Vector Laboratories, Burlingame, CA), in accordance with the supplied instructions. Kidney sections were incubated at $4^{\circ} \mathrm{C}$ overnight with primary antibodies against human tissue kallikrein (Chao et al., 1985) and the monocyte/macrophage marker ED-1 (diluted 1:100; Chemicon, Temecula, CA). The number of monocytes/macrophages was counted as positive staining of ED1 in a blinded manner from 10 different fields of each section at $\times 200$ magnification.

\section{TUNEL staining}

Apoptotic cells were visualized in a terminal deoxynucleotidyltransferase-mediated dUTP nick end labeling (TUNEL) assay and costained with propidium iodide (PI) (Chao et al., 2007). The TUNEL procedure was performed with an in situ cell death detection kit (Roche, Indianapolis, IN) according to the manufacturer's instructions. TUNELpositive apoptotic tubular epithelial cells were counted under blinded conditions in 10 consecutive fields at $\times 200$ magnification in the outer stripe of the medulla.

\section{Western blot analysis}

Western blot analysis was performed with the cytosolic fraction of kidney extracts and cell lysates from cultured proximal tubular cells to detect total and phosphorylated forms of p38 mitogen-activated protein kinase (p38 $8^{\text {MAPK})}$ and Akt (Cell Signaling Technology, Beverly, MA). Polyvinylidene difluoride (PVDF) membranes were incubated with secondary antibody conjugated to LumiGLO chemiluminescent reagent (Cell Signaling Technology). Chemiluminescence was detected with an ECL-Plus kit (PerkinElmer Life and Analytical Sciences, Boston, MA).

\section{Quantitative real-time polymerase chain reaction}

Total RNA was extracted from kidney with TRIzol reagent (Invitrogen, Carlsbad, CA). cDNA was transcribed with a cDNA archive kit (Applied Biosystems, Foster City, CA). Quantitative reverse transcription-polymerase chain reactions (qPCR) were carried out on a 7300 real-time PCR system (Applied Biosystems) with $10 \mu \mathrm{l}$ of $2 \times$ TaqMan universal PCR master mix, $1 \mu \mathrm{l}$ of $20 \times$ TaqMan gene expression assay mix (Rn00564227_m1 for intercellular adhesion molecule [ICAM]-1, Rn00580555_m1 for monocyte chemotactic protein [MCP]-1, Rn99999017_m1 for tumor necrosis factor [TNF]- $\alpha$, and Rn00561646_m1 for inducible nitric oxide synthase [iNOS]; Applied Biosystems), and $9 \mu \mathrm{l}$ of cDNA in duplicate under the following thermal cycler conditions: $95^{\circ} \mathrm{C}$ for $10 \mathrm{~min}$, followed by 40 cycles of $95^{\circ} \mathrm{C}$ for $15 \mathrm{sec}$ and $60^{\circ} \mathrm{C}$ for $1 \mathrm{~min}$. Transcription of the housekeeping gene encoding glyceraldehyde-3-phosphate dehydrogenase (GAPDH) was used as an internal control.

\section{Survival of proximal tubular cells}

Immortalized rat proximal tubular cells (IRPTCs; a gift from J. Ingelfinger and S.-S. Tang, Harvard Medical School, Boston, MA) were cultured in DMEM supplemented with 4 $\mathrm{mM}$ L-glutamine, sodium bicarbonate (1.5 g/liter), glucose (4.5 g/liter), $1 \times$ nonessential amino acids, and 5\% fetal calf serum at $34^{\circ} \mathrm{C}$ in an atmosphere of $95 \%$ air and $5 \% \mathrm{CO}_{2}$. Once cells reached $70 \%$ confluency, the cells were incubated with $\mathrm{H}_{2} \mathrm{O}_{2}(0.75 \mathrm{mM})$, with or without tissue kallikrein $(0.2 \mu M)$ or bradykinin $(0.1 \mu \mathrm{M})$ for $24 \mathrm{hr} . \mathrm{H}_{2} \mathrm{O}_{2}$ concentrations from 0.5 to $1.5 \mathrm{mM}$ were tested for cell injury as previously described (Cuttle et al., 2001). We selected $\mathrm{H}_{2} \mathrm{O}_{2}(0.75 \mathrm{mM})$ for this study because at this concentration $\mathrm{H}_{2} \mathrm{O}_{2}$ induced the highest level of cell injury with minimal detachment. Cellular apoptosis and cell survival were determined by Hoechst 33342 staining and 3-(4,5-dimethylthiazol-2-yl)-5-(3-carboxymethoxyphenyl)-2-(4-sulfophenyl)-2H-tetrazolium (MTS) assay, respectively. Western blot for total and phosphorylated Akt was also performed. The number of viable cells was assessed by the CellTiter $96 \mathrm{AQ}_{\text {ueous }}$ nonradioactive cell proliferation assay (Promega). Briefly, proximal tubular cells were seeded in 24-well plates and incubated with $\mathrm{H}_{2} \mathrm{O}_{2}(0.75 \mathrm{mM})$ for $24 \mathrm{hr}$. MTS solution was then added to each well and the cells were incubated in a humidified incubator at $34^{\circ} \mathrm{C}$ in $5 \% \mathrm{CO}_{2}$ for $2 \mathrm{hr}$. The quantity of formazan product present was determined by measuring the absorbance at $490 \mathrm{~nm}$.

\section{Statistical analysis}

Data were analyzed by standard statistical methods and analysis of variance (ANOVA) followed by Fisher's protected least significant difference (PLSD) and Bonferroni post hoc tests when appropriate. Group data were expressed as means \pm SEM. Values of all parameters were considered significantly different at a value of $p<0.05$.

\section{Results}

\section{Generation and characterization of MSCs expressing human tissue kallikrein}

Cultured MSCs isolated from adult bone marrow were identified morphologically on the basis of fibroblast-like spindle shape, and were characterized by immunocytochemical staining with vimentin and $\alpha$-SMA (Fig. 1A). Transduction of adenovirus into MSCs resulted in a transduction efficiency of 70-80\%, as confirmed by GFP fluorescence (Fig. 1A). After MSC transduction, the expression of human tissue kallikrein was identified by immunocytochemistry (Fig. 1A). Immunoreactive human tissue kallikrein levels in the culture medium were measured by ELISA for 3 weeks, with peak levels between 4 and 11 days after transduction (Fig. 1B). Moreover, 4 days after transduction, the VEGF level in the medium of TK-MSCs was significantly higher than that of GFP-MSCs $(p<0.05$; Fig. $1 C)$. To reach maximal expression of human tissue kallikrein in vivo, MSCs were injected into rats 4 days after transduction.

\section{TK-MSCs are resistant to $\mathrm{H}_{2} \mathrm{O}_{2}$-induced apoptosis}

Representative images of apoptotic cells identified by Hoechst staining showed reduced $\mathrm{H}_{2} \mathrm{O}_{2}$-induced apoptosis 
A

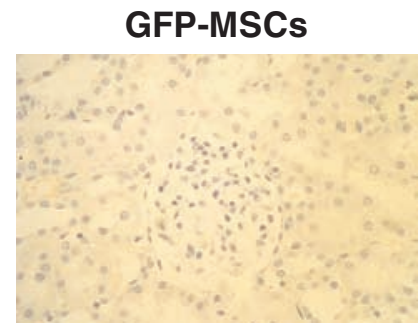

TK-MSCs (6 hr)

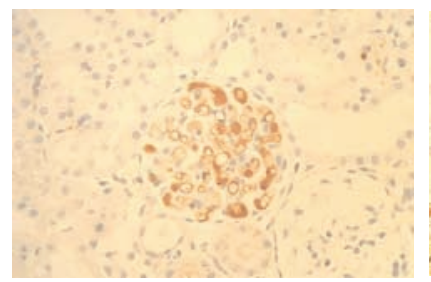

TK-MSCs (48 hr)

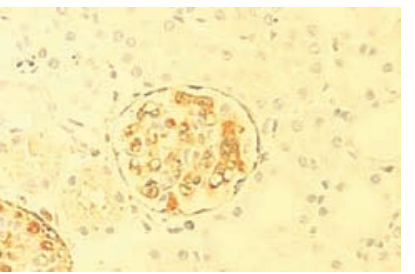

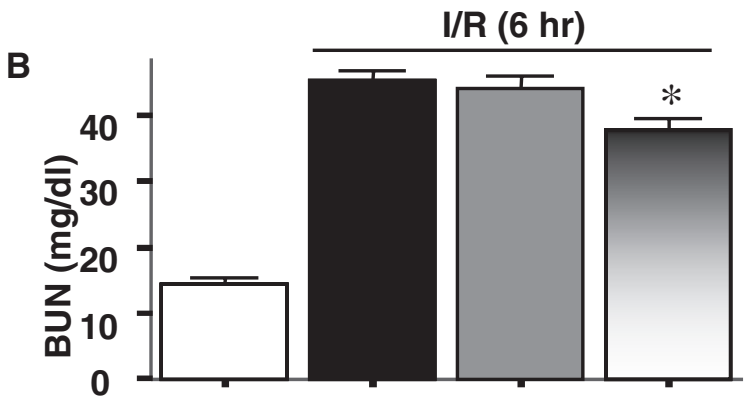

C

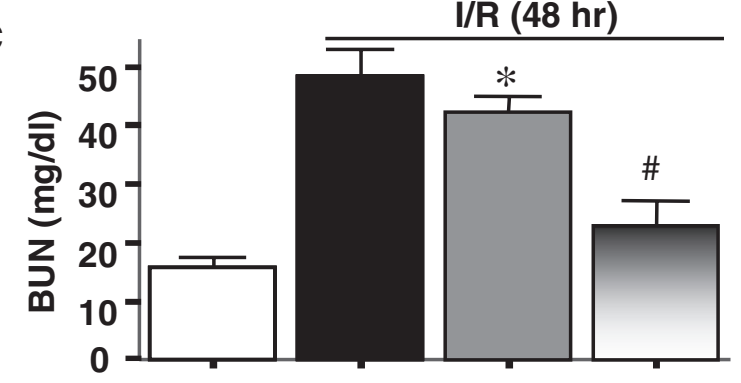

I/R (6 hr)
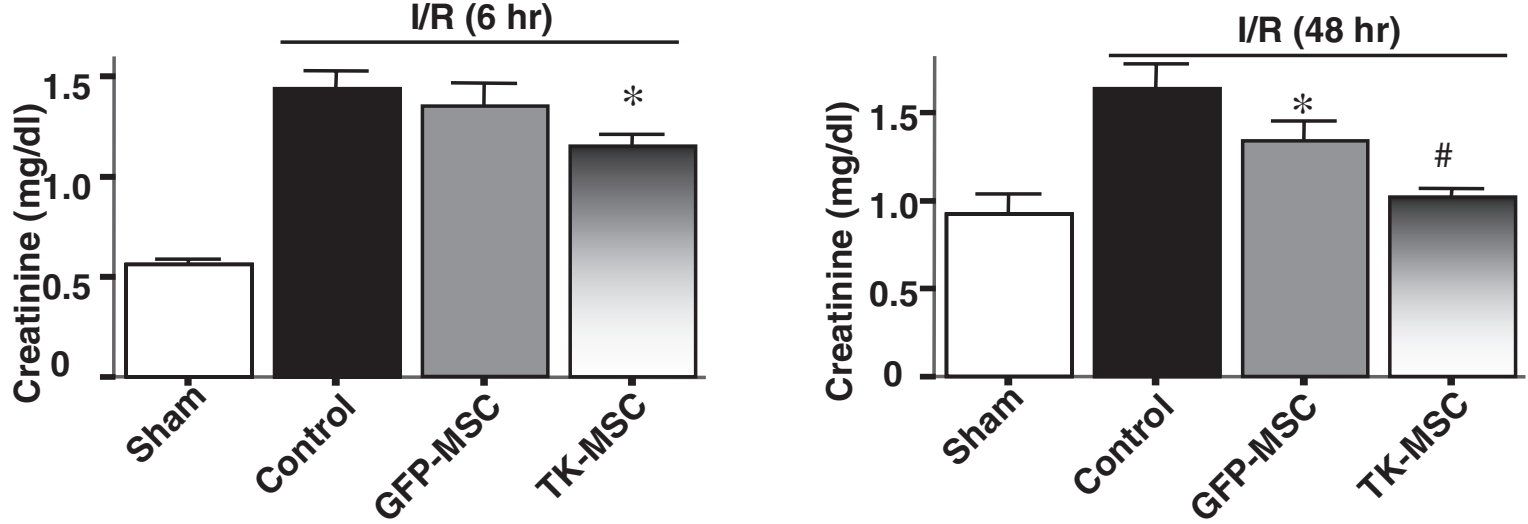

FIG. 2. Expression of human tissue kallikrein in the kidney and the effect of TK-MSCs on renal I/R injury. (A) Representative photomicrographs of immunohistochemical staining of human tissue kallikrein in kidney 6 and 48 hr after TKMSC implantation. Original magnification, $\times 400$. (B and C) BUN and creatinine levels 6 and 48 hr after I/R. Values are expressed as means \pm SEM, $n=6-8$ ( ${ }^{*} p<0.05$ vs. I/R; ${ }^{\#} p<0.05$ vs. I/R + GFP-MSCs).

in TK-MSCs compared with MSCs and GFP-MSCs after $6 \mathrm{hr}$ (Fig. 1D). Quantitative analysis verified these results $(p<$ 0.05 ; Fig. 1E). Moreover, caspase-3 activity was significantly reduced in the TK-MSC group compared with the MSC and GFP-MSC groups subjected to $\mathrm{H}_{2} \mathrm{O}_{2}$ treatment for $6 \mathrm{hr}(p<$ 0.05 ; Fig. 1F). These combined results indicate that kallikreinmodified MSCs are more resistant to oxidative stress-induced apoptosis than are control MSCs and GFP-MSCs (Fig. 1D-F).

\section{TK-MSCs reduce I/R-induced renal injury}

To evaluate the effect of TK-MSCs in I/R-induced kidney injury, GFP-MSCs or TK-MSCs were injected via the carotid artery within $1 \mathrm{hr}$ of reperfusion. Expression and localization of human tissue kallikrein in rat kidney were identified in the glomeruli of the I/R + TK-MSC group, but not in the I/R + GFP-MSC group, 6 and $48 \mathrm{hr}$ after I/R (Fig. 2A). Immunoreactive human tissue kallikrein was identified only in rats injected with TK-MSCs after I/R, because the antibody had no cross-reactivity with endogenous rat tissue kallikrein.
BUN and creatinine levels in the I/R + TK-MSC group were significantly reduced compared with the control I/ $\mathrm{R}$ group at $6 \mathrm{hr}$ after I/R ( $p<0.05$; Fig. 2B). Moreover, BUN and creatinine levels in the I/R + TK-MSC group were significantly reduced as compared with both control I/R and I/R + GFPMSC groups $48 \mathrm{hr}$ after I/R ( $p<0.05$; Fig. $2 \mathrm{C})$. These results indicate that expression of human tissue kallikrein after TKMSC implantation attenuated I/R-induced renal dysfunction after acute I/R injury. Because I/R injury results in massive tubular injury, we examined morphological changes 48 hr after reperfusion (Fig. 3A). The sham group had normal renal morphology. However, I/R resulted in notable damage in the cortex and the corticomedullary junction, including tubular necrosis, congestion of tubules with debris, tubular dilatation, accumulation of protein casts, and loss of brush border. Compared with the I/R group, GFP-MSC engraftment decreased kidney injury as indicated by fewer necrotic tubules, dilated tubules, and protein casts, and attenuation of brush border loss. However, implantation of TK-MSCs further reduced renal damage compared with the $\mathrm{I} / \mathrm{R}+$ GFP-MSC group. Quantitative analysis showed that 
A

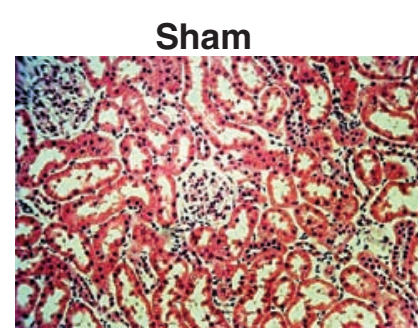

I/R+GFP-MSCs

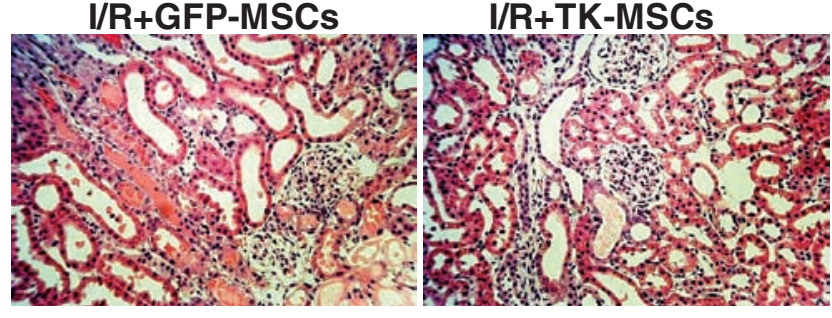

B

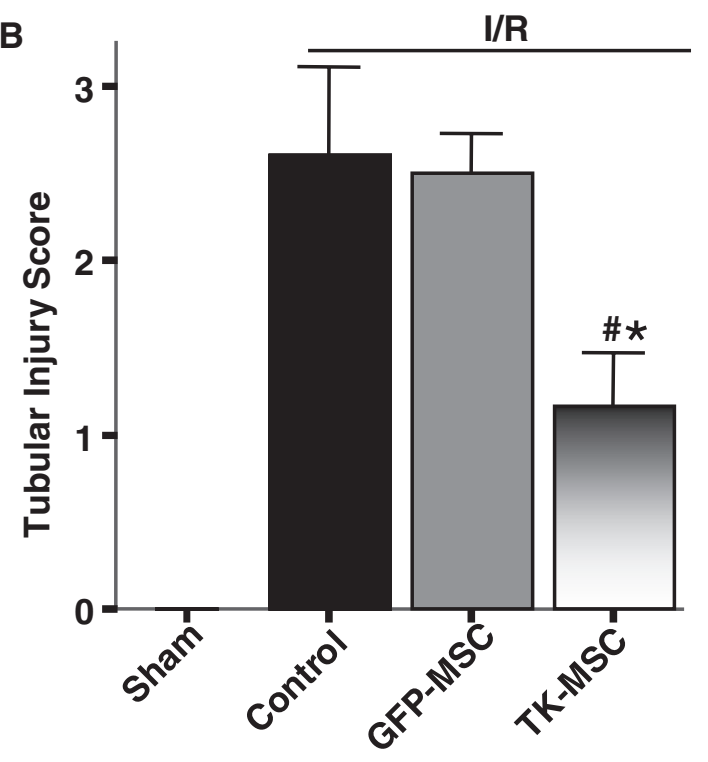

I/R

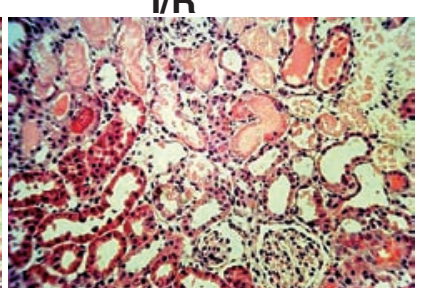

I/R+TK-MSCs

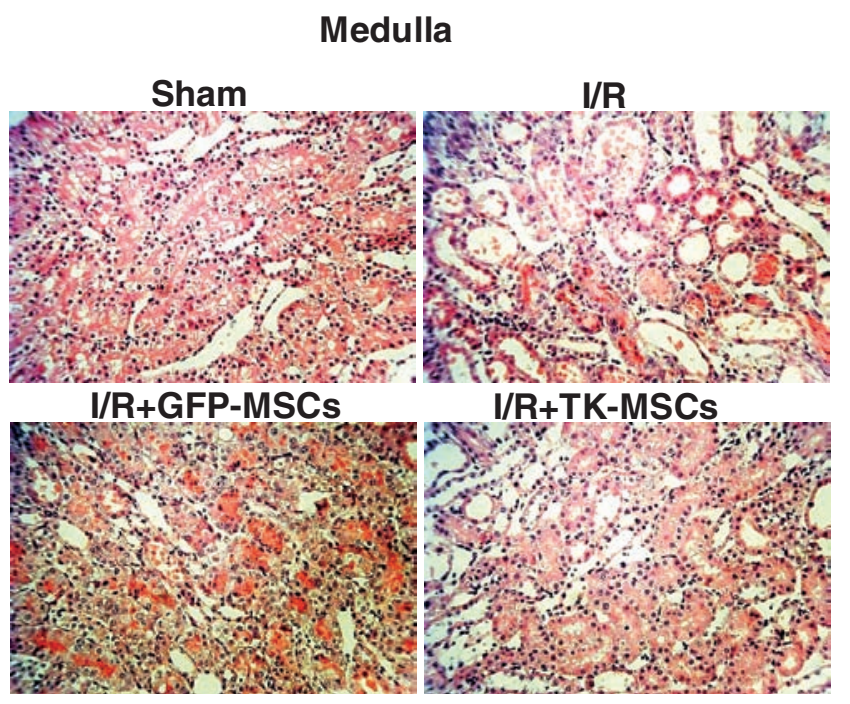

Medulla

FIG. 3. TK-MSCs ameliorate tubular injury $48 \mathrm{hr}$ after I/R. (A) Representative images of histological staining with PAS in kidney cortex and medulla. Original magnification, $\times 200$. (B) Semiquantitative analysis of tubular damage. Values are expressed as means \pm SEM, $n=6-8\left({ }^{*} p<0.05\right.$ vs. $\mathrm{I} / \mathrm{R} ;{ }^{*} p<0.05$ vs. I/R + GFP-MSCs).

both I/R and I/R + GFP-MSC groups had higher proximal tubular injury scores compared with sham-operated rats, and that GFP-MSC implantation failed to reduce tubular injury score as compared with the I/R group. TK-MSC implantation significantly reduced damage scores compared with both I/R and I/R + GFP-MSC groups (Fig. 3B).

\section{TK-MSCs reduce renal cell apoptosis, NO levels, and iNOS expression after $I / R$}

Figure 4A shows representative images of TUNEL-positive apoptotic cells in the outer stripe of the medulla $6 \mathrm{hr}$ after I/R. There was little positive staining in specimens of the sham group, but numerous apoptotic cells were observed in medulla and cortex in the I/R group. Implantation of GFPMSCs reduced apoptotic cells compared with the I/R group, and TK-MSCs further reduced renal cell apoptosis. Quantitative analysis showed that TK-MSCs significantly reduced $\mathrm{I} / \mathrm{R}$-induced renal cell apoptosis compared with the I/R and I/R + GFP-MSC groups $(p<0.05$; Fig. 3B). Excessive

amounts of $\mathrm{NO}$ and subsequent peroxynitrite in the initial phase after I/ $R$ have been reported to possibly mediate tubular injury (Vinas et al., 2007). In this regard, we measured NO content in kidney tissue $6 \mathrm{hr}$ after I/R. Renal NOx content in the I/R group increased significantly compared with that of the sham group $(p<0.05)$, whereas TK-MSCs significantly reduced NO levels ( $p<0.05 ;$ Fig. $4 \mathrm{C}$ ). In addition, the mRNA expression of iNOS was significantly reduced in the $\mathrm{I} / \mathrm{R}+\mathrm{TK}-\mathrm{MSC}$ group compared with the I/R group $(p<$ 0.05 ; Fig. 4D). These results indicate that in the initial phase of I/R injury, TK-MSC protection against renal cell apoptosis could be mediated in part by suppression of iNOS expression and NO formation.

\section{TK-MSCs reduce inflammatory cell infiltration and reactive oxygen species formation}

Augmentation of apoptosis after acute I/R is believed to cause inflammation and further generation of reactive oxygen species (ROS). First, we inspected the effect of TK-MSCs 
A

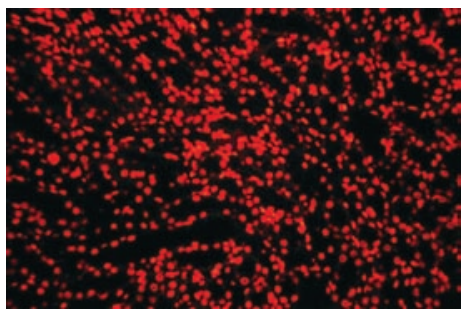

I/R+GFP-MSCs

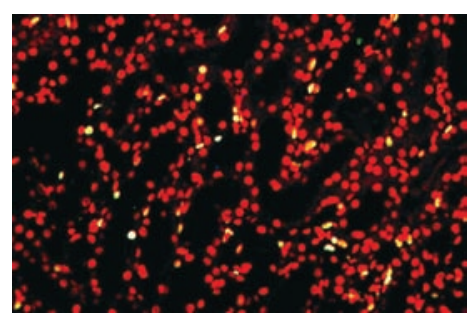

I/R

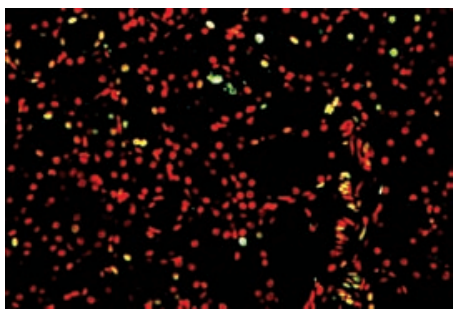

I/R+TK-MSCs

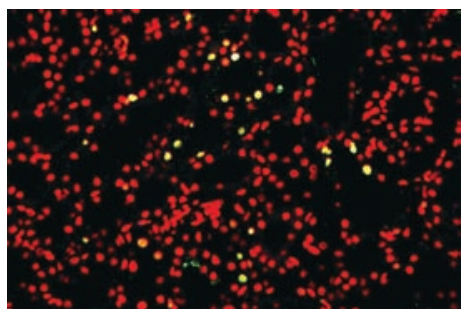

B

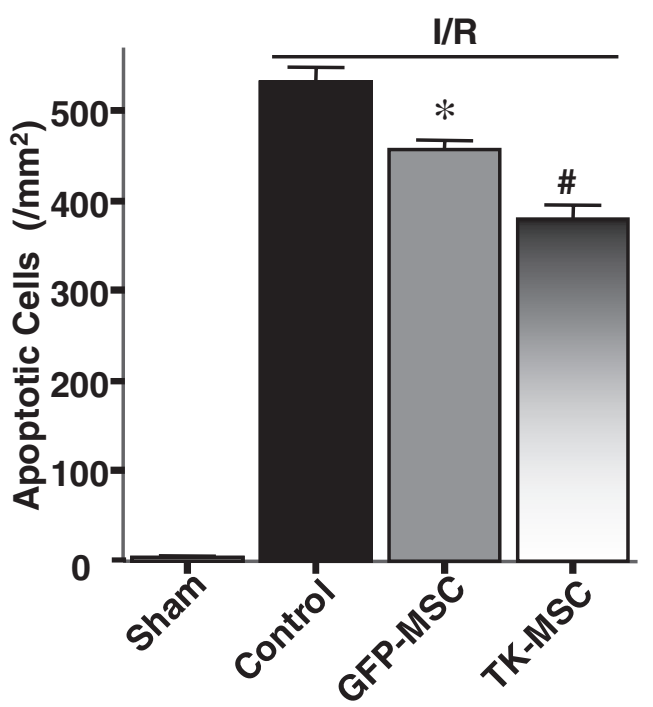

C

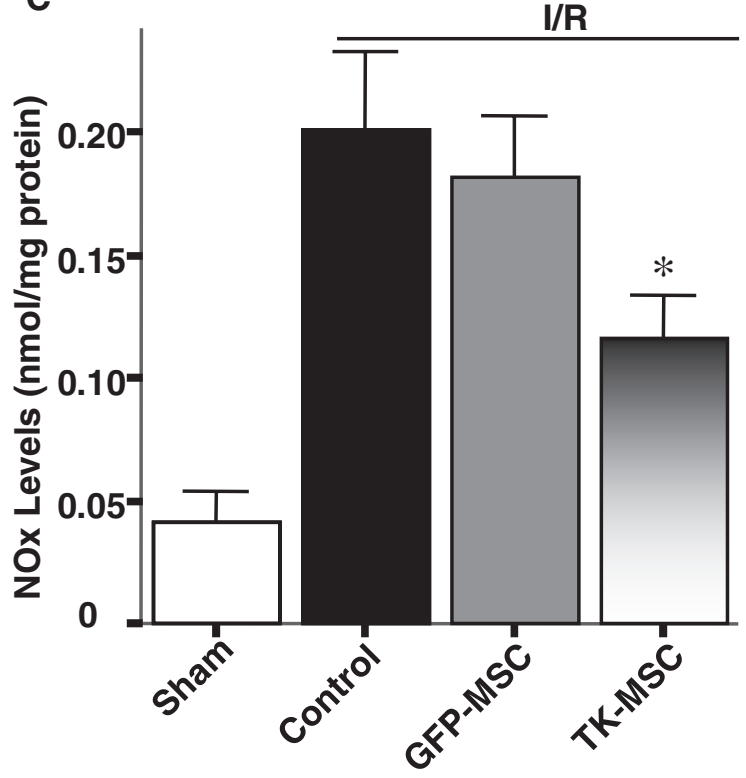

D

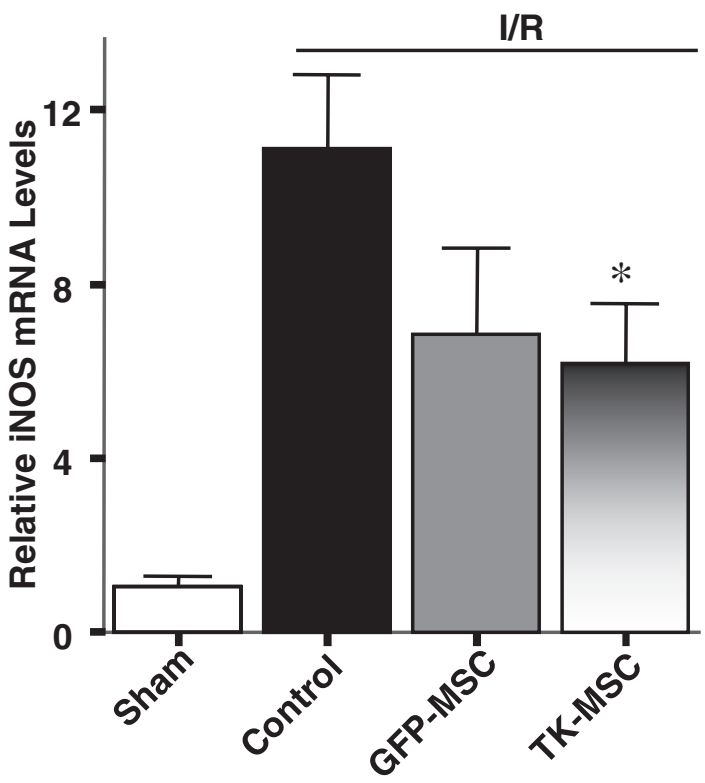

FIG. 4. TK-MSCs reduce renal cell apoptosis, NO, and iNOS mRNA expression $6 \mathrm{hr}$ after I/R. (A) Representative images of TUNEL staining. Propidium iodide stains red and TUNEL stains green; yellow is overlay. Original magnification, $\times 200$. (B) Apoptotic tubular cells in the outer stripe of the medulla. (C) Nitrate/nitrite (NOx) content and (D) mRNA levels of iNOS in kidney tissue. Values are expressed as means \pm SEM, $n=6-8$ ( ${ }^{*} p<0.05$ vs. I/R; ${ }^{*} p<0.05$ vs. I/R + GFP-MSCs).

on monocyte/macrophage and neutrophil infiltration. Representative ED-1 immunostaining and quantitative analysis in the kidney $48 \mathrm{hr}$ after I/R showed that macrophage number was markedly higher in the I/R group than in the sham group $(p<0.05)$, and was significantly reduced after MSC administration ( $p<0.05$; Fig. 5A and B). However, there was no significant difference between the I/R + GFP-MSC and I/R + TK-MSC groups. Moreover, neutrophil accumulation identified by H\&E staining was significantly higher in the $\mathrm{I} / \mathrm{R}$ group than in the sham group $(p<0.05)$. TK-MSCs significantly reduced neutrophil number compared with both I/R and I/R + GFP-MSC groups ( $p<0.05$; Fig. $5 \mathrm{C})$.
Myeloperoxidase (MPO) activity in kidney tissue of the $\mathrm{I} / \mathrm{R}+$ TK-MSC group was significantly decreased compared with the control I/R group ( $p<0.05$; Fig. 6A). In addition, superoxide formation in the I/ $R$ group was higher than that of the sham group, and TK-MSCs significantly reduced superoxide production compared with the I/R group ( $p<0.05$; Fig. 6B). The inhibitory effect of TK-MSCs on ROS formation paralleled the reduction in $\mathrm{p} 38^{\mathrm{MAPK}}$ phosphorylation (Fig. $6 \mathrm{C})$. Expression of the proinflammatory mediators TNF- $\alpha$, MCP-1, and ICAM-1 was significantly reduced in the I/R + TK-MSC group compared with the I/R control group $(p<$ $0.05)$. However, TNF- $\alpha$ and ICAM-1 expression did not reach 
A
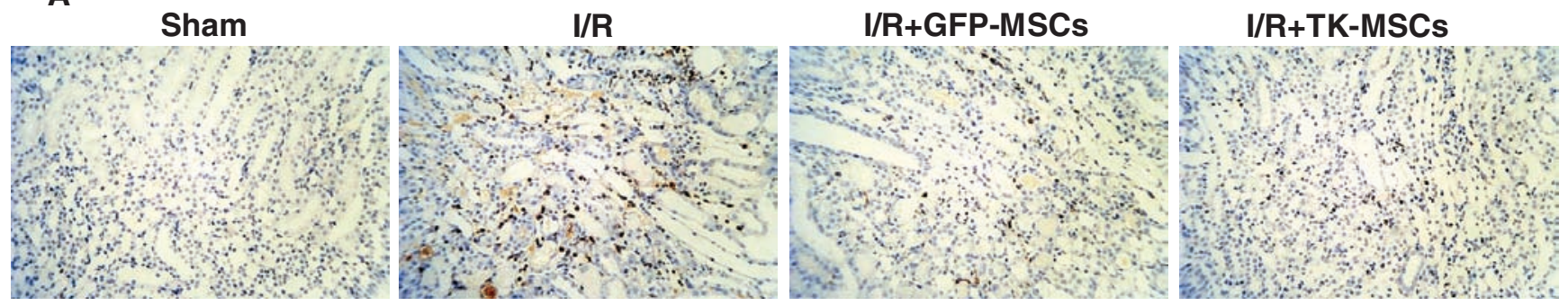

B

I/R

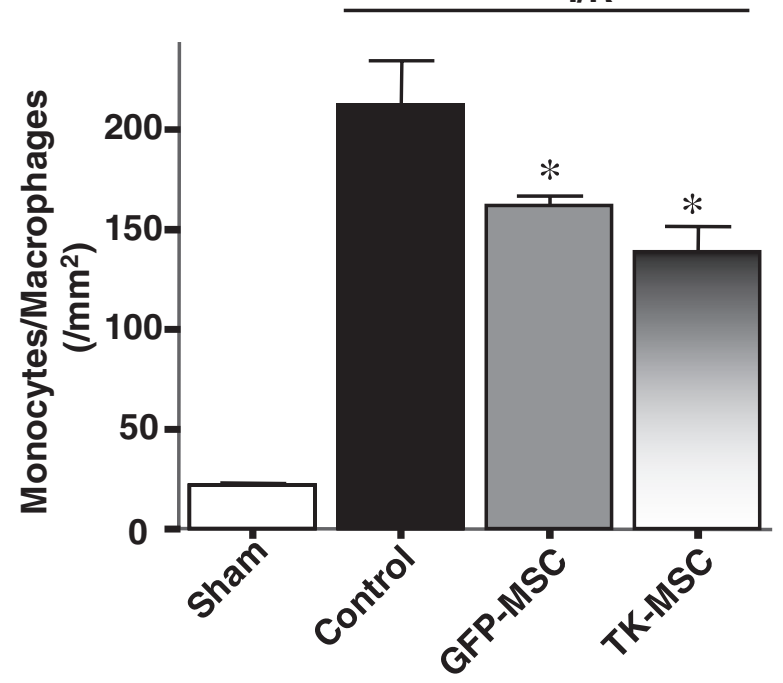

C

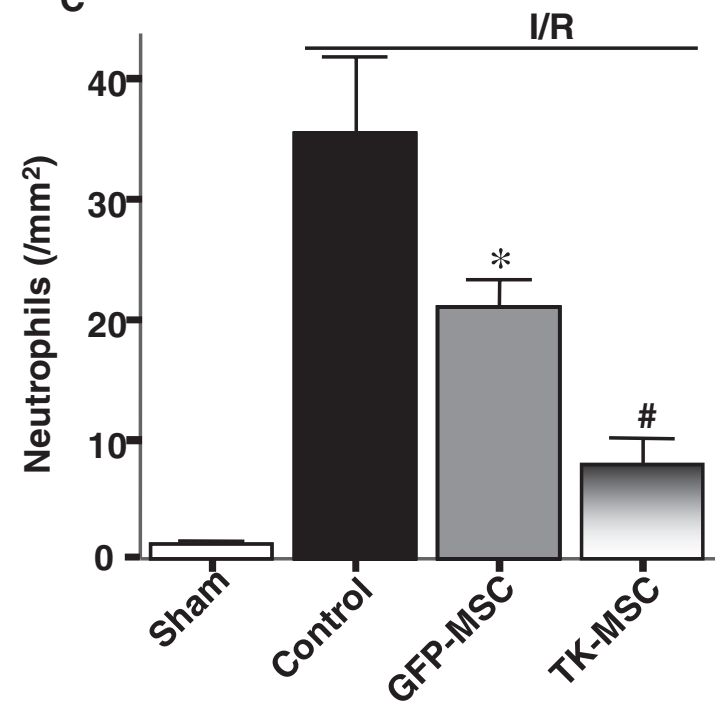

FIG. 5. TK-MSCs reduce monocyte/macrophage and neutrophil accumulation in the renal interstitium $48 \mathrm{hr}$ after I/R. (A) Representative images of immunohistochemical staining for ED-1, a specific marker for monocytes/macrophages. Original magnification, $\times 200$. Quantitative analysis of (B) ED-1-positive cells and (C) neutrophils. Values are expressed as means \pm SEM, $n=6-8$ ( ${ }^{*} p<0.05$ vs. I/R; ${ }^{\#} p<0.05$ vs. I/R + GFP-MSCs).

statistical significance between the I/R + TK-MSC and $\mathrm{I} / \mathrm{R}+\mathrm{GFP}-\mathrm{MSC}$ groups.

\section{Tissue kallikrein and kinin reduce $\mathrm{H}_{2} \mathrm{O}_{2}$-induced apoptosis of cultured renal proximal tubular cells}

Figure 7A shows representative apoptotic tubular cells treated with $\mathrm{H}_{2} \mathrm{O}_{2}$ for $24 \mathrm{hr}$. Analysis of high-power fields showed that incubation with $\mathrm{H}_{2} \mathrm{O}_{2}$ caused cell injury indicated by cellular detachment, fragmentation of the nucleus, and condensation of chromatin. However, kallikrein (TK) and bradykinin (BK) reduced the number of apoptotic tubular cells compared with the $\mathrm{H}_{2} \mathrm{O}_{2}$-treated group. The antiapoptotic effect of TK and BK was verified by quantitative analysis ( $p<0.01 ;$ Fig. 7B). Moreover, TK and BK improved cell viability as measured by MTS assay $(p<0.01$; Fig. 7C). Even though Akt phosphorylation was rapidly increased 10 min after $\mathrm{H}_{2} \mathrm{O}_{2}$ treatment with or without TK and BK coincubation (data not shown), the effect of TK and BK in inhibiting oxidative stress-induced renal cell apoptosis was accompanied by a significant increase in Akt phosphorylation after coincubation with $\mathrm{H}_{2} \mathrm{O}_{2}$ for $24 \mathrm{hr}(p<0.05$; Fig. 7D). These results indicate that tissue kallikrein/kinin protects against oxidative stress-induced renal tubular cell apoptosis by Akt-mediated signaling.

\section{Discussion}

This study demonstrates that a combined stem cell and kallikrein gene approach provides advanced benefits in healing injured kidney in a setting of acute renal failure. Our results showed that kallikrein-modified MSCs, after systemic injection, migrated to the injured kidney after I/R. Expression of human tissue kallikrein in rat kidney after TK-MSC implantation exhibited enhanced protection against renal injury by inhibiting apoptosis and inflammatory cell infiltration. TK-MSCs secreted recombinant human tissue kallikrein into culture medium and significantly improved stem cell survival during oxidative stress. Moreover, tissue kallikrein and kinin also inhibited oxidative stress-induced apoptosis in proximal tubular cells. These combined findings indicate that renal protection by TK-MSC implantation could be attributed to both autocrine and paracrine mechanisms. Our previous studies showed that tissue kallikrein/kinin replacement by gene delivery or protein infusion protects against organ damage with antioxidative, antiapoptotic, antiinflammatory, and angiogenic effects (Xia et al., 2004; Zhang et al., 2004; Yao et al., 2007). Taken together, the current study suggests that engraftment of genetically modified MSCs with tissue kallikrein is a superior strategy in protection against ARF through both the pleiotropic effects of kallikrein and 
A
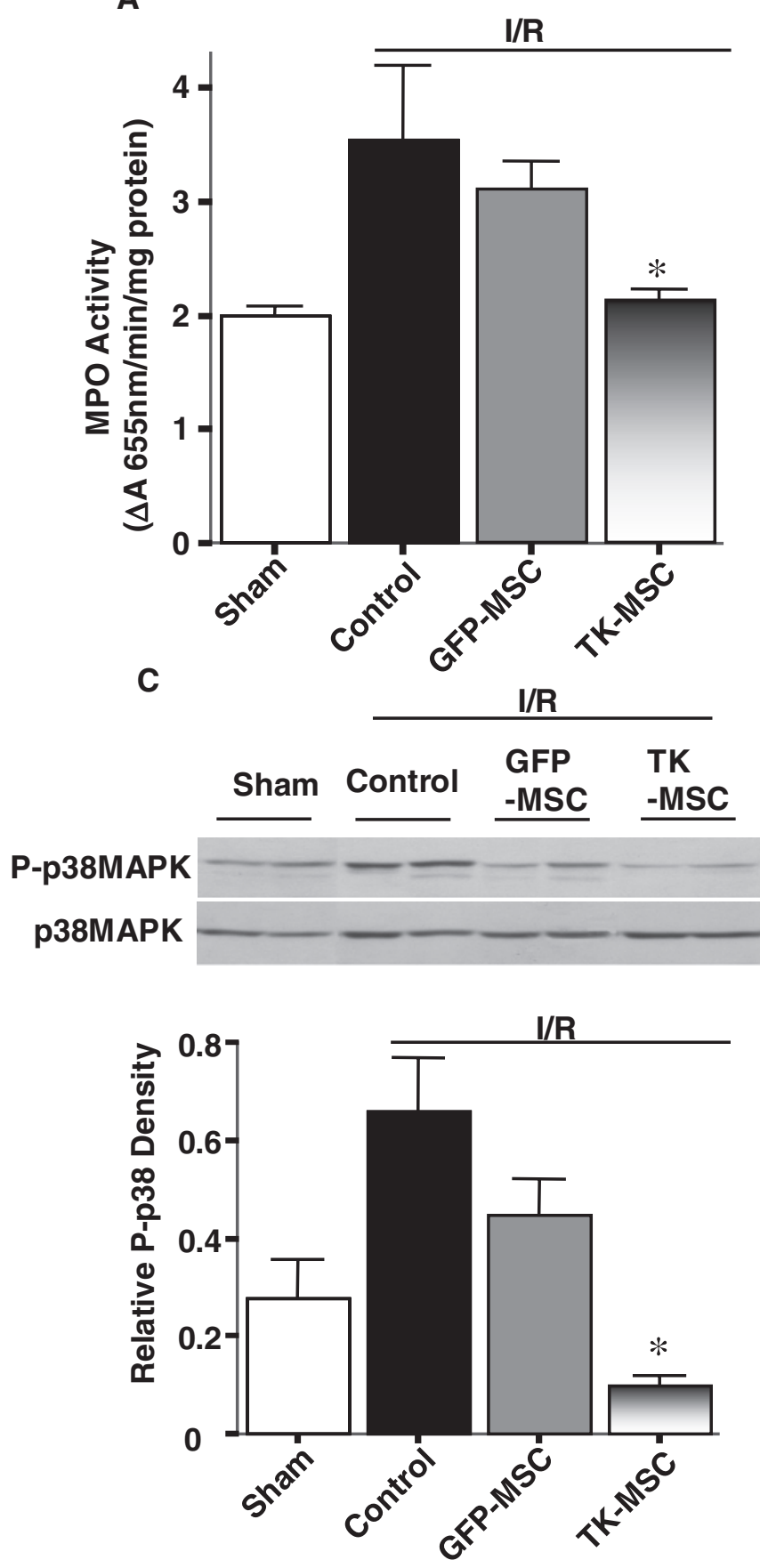

B

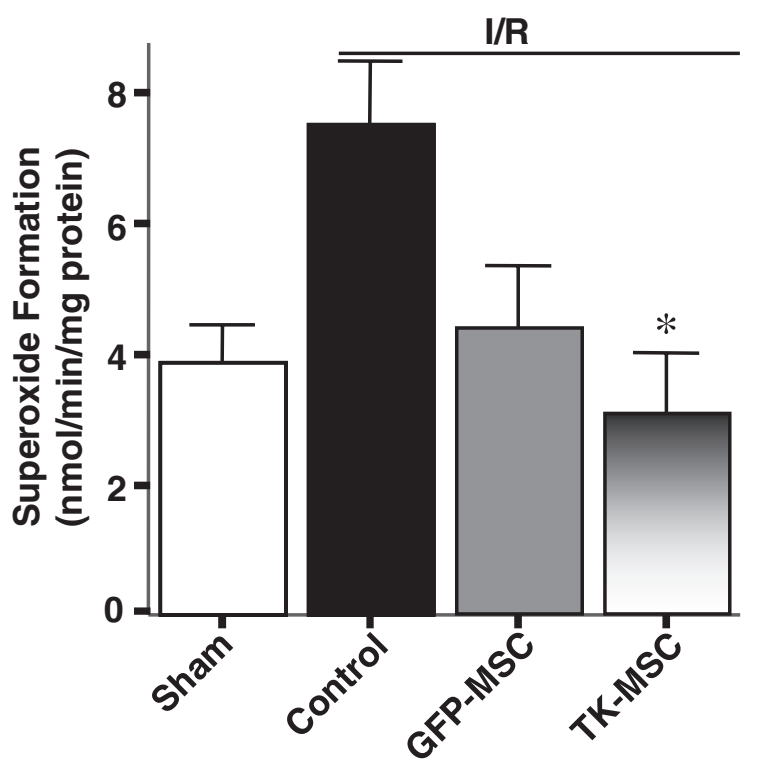

FIG. 6. TK-MSCs reduce oxidative stress, p38MAPK phosphorylation, and inflammatory mediator expression $48 \mathrm{hr}$ after I/R. (A) MPO activity and (B) superoxide formation in kidney tissue. (C) Representative Western blot of phosphorylated and total p38 (top) and densitometric analysis (bottom). Relative mRNA levels of (D) TNF- $\alpha$, (E) MCP-1, and (F) ICAM1 determined by real-time PCR. Values are expressed as means $\pm \mathrm{SEM}, n=6-8\left({ }^{*} p<0.05\right.$ vs. I/R; ${ }^{*} p<0.05$ vs. I/R + GFP-MSCs).
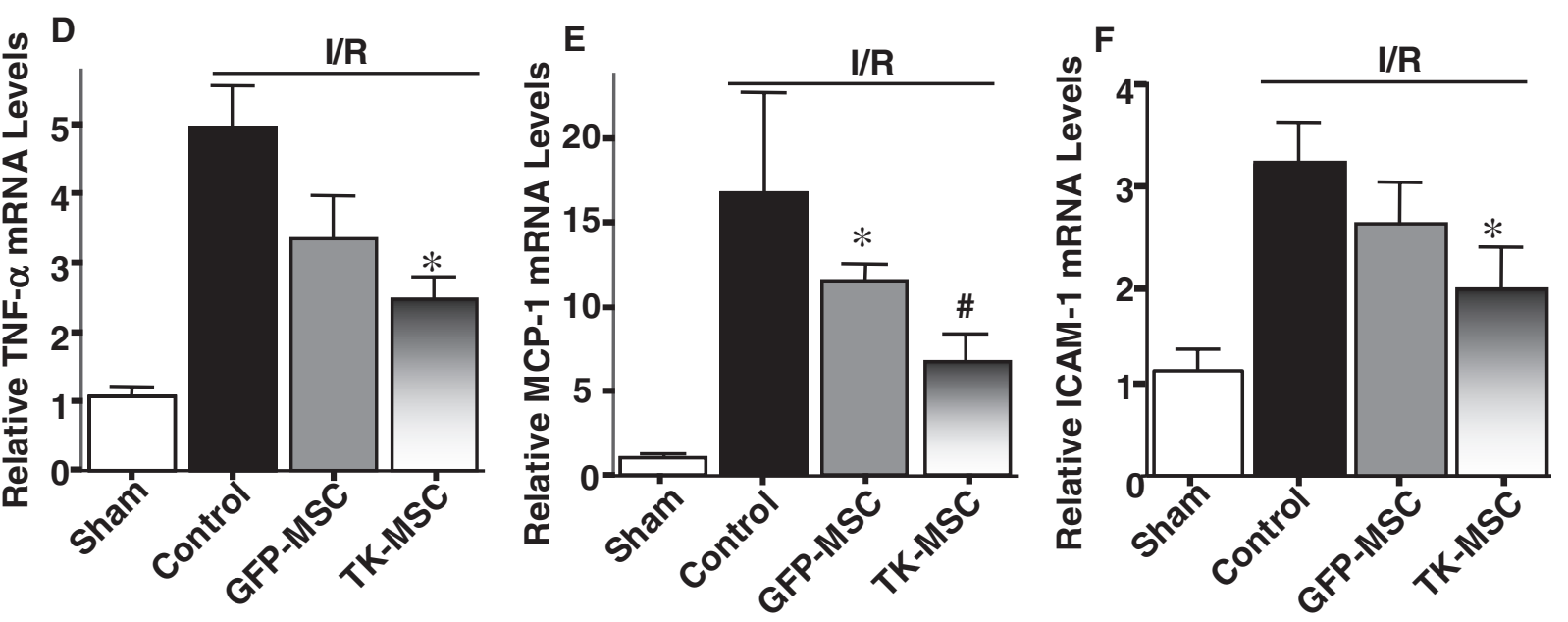

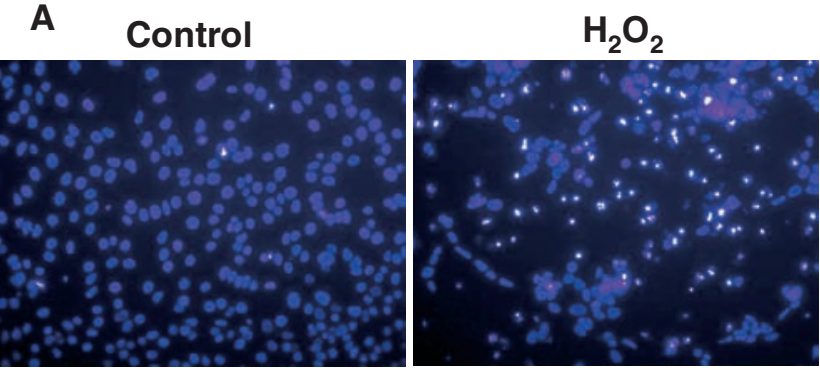

B
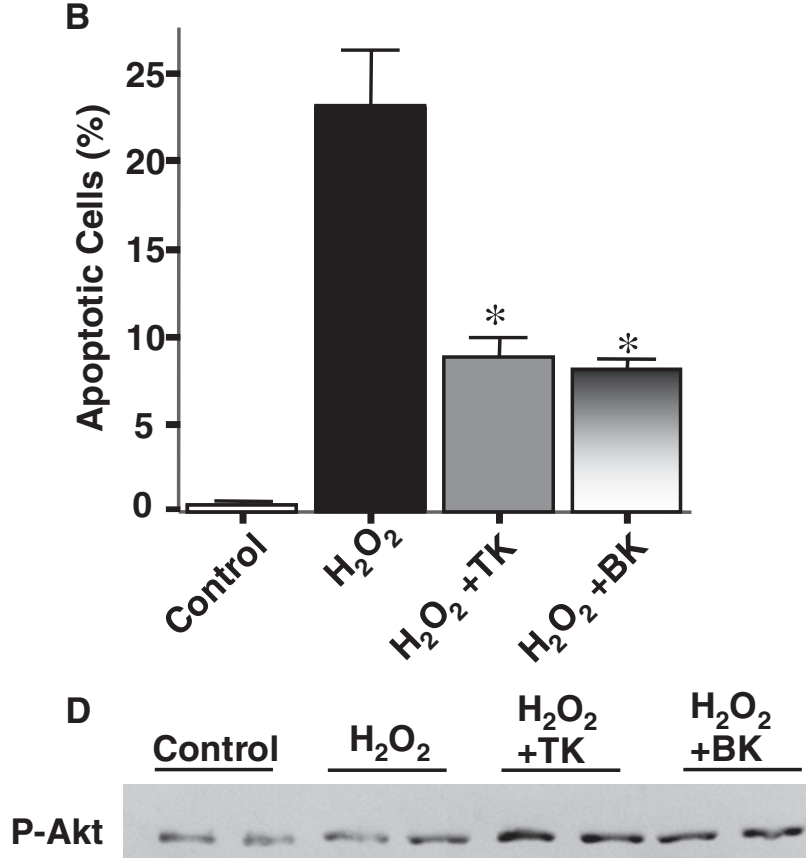

Akt

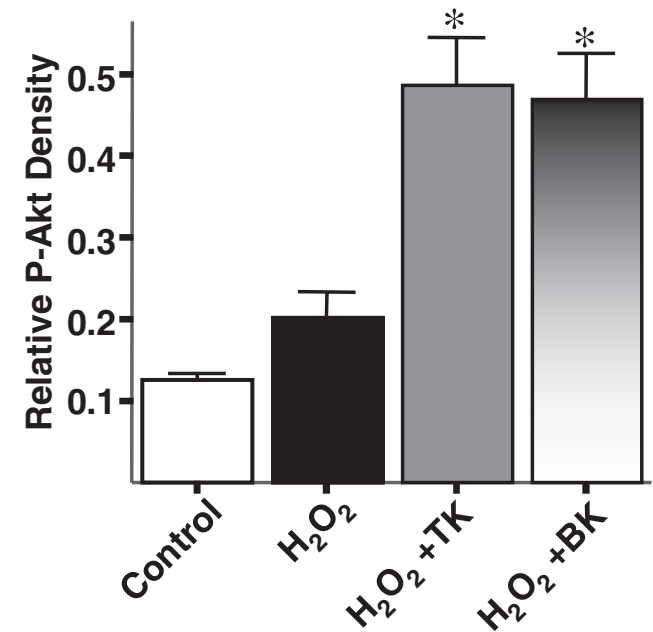

MSC-mediated paracrine actions. Even though our investigations were limited to two time points in the early phase of $\mathrm{ARF}$, these results indicate a promising strategy to treat chronic kidney diseases.

Stem cells are ideal for cell therapy of various ischemic diseases, given their multipotency, low immunogenicity, and
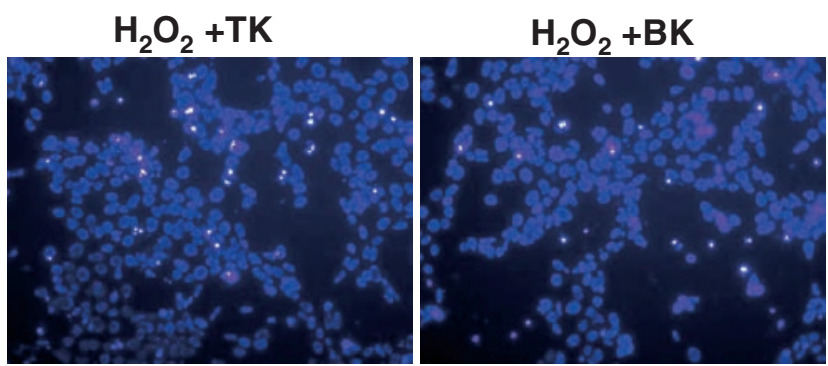

C

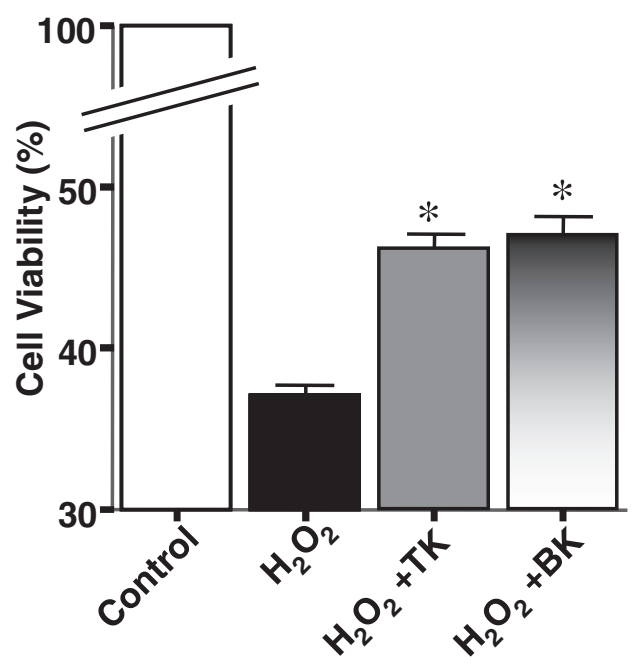

FIG. 7. Tissue kallikrein (TK) and bradykinin (BK) inhibit cell injury induced by $\mathrm{H}_{2} \mathrm{O}_{2}$. (A) Representative Hoechst staining of proximal tubular cells treated with $\mathrm{H}_{2} \mathrm{O}_{2}$ for $24 \mathrm{hr}$. (B) Quantitative analysis of apoptotic MSCs expressed as a percentage of total cell number. (C) Cell viability of IRPTCs assessed by MTS assay after incubation with $\mathrm{H}_{2} \mathrm{O}_{2}$ for 24 hr. (D) Representative Western blot of phosphorylated and total Akt (top) and densitometric analysis (bottom). Values are expressed as means \pm SEM, $n=6\left({ }^{*} p<0.05\right.$ vs. $\left.\mathrm{H}_{2} \mathrm{O}_{2}\right)$. amenability to ex vivo expansion. However, implanted MSCs are highly sensitive to hypoxia and the inflammatory environment of ischemic tissues. Nevertheless, Togel and coworkers $(2005,2007)$ demonstrated that MSCs are protective against ischemic kidney injury. Moreover, no significant difference in postmyocardial infarction cardiac remodeling 
was observed between unmodified MSCs and MSCs transduced with a reporter gene (Tang et al., 2005). Thus, incorporation of a control gene, such as GFP, into MSCs is unlikely to affect the protective capabilities of MSCs against organ damage. Stem cells engineered with antiapoptotic and antioxidant genes can improve MSC survival in ischemic tissue and thus enhance the efficiency of repair. For example, Tang and coworkers (2005) demonstrated that a higher number of MSCs transduced with the heme oxygenase (HO)-1 gene survive when injected into infarcted hearts compared with control MSCs, leading to more efficient healing. Similarly, Mangi and coworkers (2003) showed that overexpression of the Akt gene greatly enhanced the survival of MSCs subjected to hypoxia/reoxygenation, and prevented pathological remodeling, with impressive improvement in cardiac output after myocardial infarction. Paracrine actions were shown to be responsible for the cardioprotective effects of Akt-MSCs (Noiseux et al., 2006). Although in the present study, expression of human tissue kallikrein after TK-MSC implantation was identified mainly in glomeruli, tissue kallikrein could also diffuse to peritubular capillaries and tubules, and thus cleave low molecular weight kininogen to release kinin into the renal tubules. Moreover, cultured TKMSCs secreted human tissue kallikrein with elevated VEGF levels in culture medium compared with control GFP-MSCs. MSCs have been shown to secrete growth factors, such as insulin-like growth factor (IGF)-I (Imberti et al., 2007), hepatocyte growth factor (HGF), and VEGF (Togel et al., 2007), that promote tubular cell proliferation and survival. Increased VEGF secretion from TK-MSCs, observed in the present study, may also contribute to renal protection (Kanellis et al., $2000 a, b)$. Therefore, it is likely that the protective actions of TK-MSCs may be attributed to both autocrine and paracrine mechanisms at the injured renal tissues.

Renal dysfunction and apoptosis/necrosis of tubular epithelial cells are of key importance for the pathophysiological consequences of ARF. Apoptosis is a crucial early event that can initiate reperfusion-induced inflammation and subsequent tissue injury. Indeed, prevention of renal cell damage after ARF with the antiapoptotic agents IGF-I and ZVAD-fmk (a caspase inactivator) can block the early onset of not only apoptosis, but also inflammation and tissue injury (Daemen et al., 1999). In this study, we demonstrated that implantation of genetically modified MSCs expressing human tissue kallikrein prevented renal cell apoptosis in the initial phase after acute I/R injury. The protective actions of TK-MSCs in ischemia-induced renal cell apoptosis may thus lead to a subsequent reduction in inflammatory cell infiltration and kidney injury. Moreover, tissue kallikrein and kinin inhibited apoptosis and promoted cell viability in conjunction with increased Akt phosphorylation in cultured proximal tubular cells after exposure to ROS. These combined results from in vivo and in vitro studies indicate that tissue kallikrein secreted from TK-MSCs protects against ROSinduced renal cell apoptosis. In this regard, we previously showed that kallikrein gene transfer significantly attenuated I/R-induced cardiomyocyte apoptosis via activation of the phosphatidylinositol-3-kinase (PI3K)-Akt-glycogen synthase kinase (GSK)-3 $\beta$ and Bcl-2 signaling pathways (Yin et al., 2005). Taken together, these findings suggest that the tissue kallikrein-kinin system may protect against oxidative stressinduced apoptosis of renal epithelial cells by activating the PI3K-Akt pathway.
Our results showed that engrafted TK-MSCs protect against ischemia-induced renal cell apoptosis and kidney injury after acute I/R. This finding is consistent with a study showing that kinin B2 and B1 receptors play an important role in reducing apoptosis and renal dysfunction during renal I/R injury in kinin receptor knockout mice (Kakoki et al., 2007). Conversely, early activation of the tissue kallikrein/ kinin B2 receptor before or during acute renal I/ R injury was shown to aggravate ROS formation and renal damage by increasing inflammatory cell infiltration and apoptosis (Chiang et al., 2006). In this study, we administered TK-MSCs within $1 \mathrm{hr}$ of reperfusion. However, Chiang and coworkers (2006) infused tissue kallikrein before or during the ischemic period. Therefore, the discrepancy may be attributed to differences in the level and location of tissue kallikrein produced, and the time period before, during, or after acute I/ $\mathrm{R}$ injury.

The reduction in renal cell apoptosis by implantation of TK-MSCs occurred in conjunction with suppression of iNOS expression and NO levels $6 \mathrm{hr}$ after I/R injury. NO is known to function as a double-edged sword (Colasanti and Suzuki, 2000). Physiological levels of NO exert beneficial effects by inhibiting NF- $\kappa \mathrm{B}$ activation; MCP-1, vascular cell adhesion molecule (VCAM)-1, and ICAM-1 expression; and monocyte/macrophage recruitment (Zeiher et al., 1995; Spiecker et al., 1998). NO can directly inhibit NADPH oxidase activity and thus superoxide formation in neutrophils (Clancy et al., 1992). In contrast, elevated NO levels can exacerbate renal injury after an acute insult (Lieberthal, 1998). Production of NO within renal tubular cells is markedly increased by acute ischemic and toxic injury and contributes to the severity of tubular injury. NO can combine with superoxide to form the peroxynitrite anion, which mediates cell death primarily by causing oxidant injury and by nitrosylating tyrosine residues in proteins (Goligorsky et al., 2002). Studies indicate that iNOS is the predominant isoform of NOS responsible for increased NO production and NO-mediated injury in cultured renal tubular cells subjected to oxidative insults (Peresleni et al., 1996). Targeted inhibition of iNOS was shown to be protective in ischemia-induced kidney damage (Chatterjee et al., 2003). Therefore, suppression of NO formation by iNOS after TK-MSC implantation may play a crucial role in protection against cell death during the early events of I/R-induced ARF.

Ischemia induces the kidney to produce a number of inflammatory factors. Factors such as interleukin (IL)-1, IL-6, and TNF- $\alpha$ induce the expression of ICAM-1, VCAM-1, and E-selectin through activation of NF- $\kappa \mathrm{B}$ and p38MAPK signaling (Prodjosudjadi et al., 1995; Kuldo et al., 2005; Thurman, 2007), whereas upregulation of MCP-1 occurs via ROS and/or extracellular signal-regulated kinase-1/2 (ERK)-1/2 (Schlondorff, 1995; De Keulenaer et al., 2000; Chen et al., 2004). Also, cell adhesion molecules expressed on the surface of endothelial cells facilitate the binding and infiltration of circulating leukocytes. This is an essential step toward inflammation, as ICAM-1-deficient mice are protected from ischemic renal injury (Kelly et al., 1996). We showed that administration of TK-MSCs inhibited interstitial neutrophil and monocyte/macrophage accumulation in the kidney in association with decreased myeloperoxidase activity, superoxide formation, p38 ${ }^{\mathrm{MAPK}}$ phosphorylation, and expression of several proinflammatory factors such as TNF- $\alpha$, MCP-1, and 
ICAM-1 48 hr after I/R. Inhibition of p38MAPK by implantation of TK-MSC may lead to suppression of NF- $\kappa$ B activation and thus expression of proinflammatory cytokines and cell adhesion molecules, with a resultant decline in renal inflammation.

\section{Acknowledgments}

This work was supported by National Institutes of Health grants DK-066350, HL-29397, and C06 RR015455 from the Extramural Research Facilities Program of the National Center for Research Resources.

\section{Author Disclosure Statement}

The authors state no conflict of interest.

\section{References}

Bledsoe, G., Shen, B., Yao, Y., Zhang, J.J., Chao, L., and Chao, J. (2006). Reversal of renal fibrosis, inflammation, and glomerular hypertrophy by kallikrein gene delivery. Hum. Gene Ther. $17,545-555$.

Chao, J., Chao, L., Tillman, D.M., Woodley, C.M., and Margolius, H.S. (1985). Characterization of monoclonal and polyclonal antibodies to human tissue kallikrein. Hypertension 7, 931-937.

Chao, J., Zhang, J.J., Lin, K.F., and Chao, L. (1998). Human kallikrein gene delivery attenuates hypertension, cardiac hypertrophy, and renal injury in Dahl salt-sensitive rats. Hum. Gene Ther. 9, 21-31.

Chao, J., Li, H.J., Yao, Y.Y., Shen, B., Gao, L., Bledsoe, G., and Chao, L. (2007). Kinin infusion prevents renal inflammation, apoptosis, and fibrosis via inhibition of oxidative stress and mitogen-activated protein kinase activity. Hypertension 49, 490-497.

Chatterjee, P.K., Patel, N.S., Sivarajah, A., Kvale, E.O., Dugo, L., Cuzzocrea, S., Brown, P.A., Stewart, K.N., Mota-Filipe, H., Britti, D., Yaqoob, M.M., and Thiemermann, C. (2003). GW274150, a potent and highly selective inhibitor of iNOS, reduces experimental renal ischemia/reperfusion injury. Kidney Int. 63, 853-865.

Chen, X.L., Zhang, Q., Zhao, R., and Medford, R.M. (2004). Superoxide, $\mathrm{H}_{2} \mathrm{O}_{2}$, and iron are required for TNF- $\alpha$-induced MCP-1 gene expression in endothelial cells: Role of Rac1 and NADPH oxidase. Am. J. Physiol. Heart Circ. Physiol. 286, H1001-H1007.

Chertow, G.M., Burdick, E., Honour, M., Bonventre, J.V., and Bates, D.W. (2005). Acute kidney injury, mortality, length of stay, and costs in hospitalized patients. J. Am. Soc. Nephrol. 16, 3365-3370.

Chiang, W.C., Chien, C.T., Lin, W.W., Lin, S.L., Chen, Y.M., Lai, C.F., Wu, K.D., Chao, J., and Tsai, T.J. (2006). Early activation of bradykinin B2 receptor aggravates reactive oxygen species generation and renal damage in ischemia/reperfusion injury. Free Radic. Biol. Med. 41, 1304-1314.

Clancy, R.M., Leszczynska-Piziak, J., and Abramson, S.B. (1992). Nitric oxide, an endothelial cell relaxation factor, inhibits neutrophil superoxide anion production via a direct action on the NADPH oxidase. J. Clin. Invest. 90, 1116-1121.

Colasanti, M., and Suzuki, H. (2000). The dual personality of NO. Trends Pharmacol. Sci. 21, 249-252.

Cuttle, L., Zhang, X.J., Endre, Z.H., Winterford, C., and Gobe, G.C. (2001). Bcl- $\mathrm{X}_{\mathrm{L}}$ translocation in renal tubular epithelial cells in vitro protects distal cells from oxidative stress. Kidney Int. 59, 1779-1788.

Daemen, M.A., van't Veer, C., Denecker, G., Heemskerk, V.H., Wolfs, T.G., Clauss, M., Vandenabeele, P., and Buurman, W.A. (1999). Inhibition of apoptosis induced by ischemia-reperfusion prevents inflammation. J. Clin. Invest. 104, 541-549.

Davani, S., Marandin, A., Mersin, N., Royer, B., Kantelip, B., Herve, P., Etievent, J.P., and Kantelip, J.P. (2003). Mesenchymal progenitor cells differentiate into an endothelial phenotype, enhance vascular density, and improve heart function in a rat cellular cardiomyoplasty model. Circulation 108(Suppl. 1), II253-II258.

De Keulenaer, G.W., Ushio-Fukai, M., Yin, Q., Chung, A.B., Lyons, P.R., Ishizaka, N., Rengarajan, K., Taylor, W.R., Alexander, R.W., and Griendling, K.K. (2000). Convergence of redox-sensitive and mitogen-activated protein kinase signaling pathways in tumor necrosis factor- $\alpha$-mediated monocyte chemoattractant protein-1 induction in vascular smooth muscle cells. Arterioscler. Thromb. Vasc. Biol. 20, 385-391.

Deng, W., Bivalacqua, T.J., Chattergoon, N.N., Hyman, A.L., Jeter, J.R., Jr., and Kadowitz, P.J. (2003). Adenoviral gene transfer of eNOS: High-level expression in ex vivo expanded marrow stromal cells. Am. J. Physiol. Cell Physiol. 285, C1322-C1329.

Goligorsky, M.S., Brodsky, S.V., and Noiri, E. (2002). Nitric oxide in acute renal failure: NOS versus NOS. Kidney Int. 61, 855-861.

Griendling, K.K., Minieri, C.A., Ollerenshaw, J.D., and Alexander, R.W. (1994). Angiotensin II stimulates NADH and NADPH oxidase activity in cultured vascular smooth muscle cells. Circ. Res. 74, 1141-1148.

Haq, M., Norman, J., Saba, S.R., Ramirez, G., and Rabb, H. (1998). Role of IL-1 in renal ischemic reperfusion injury. J. Am. Soc. Nephrol. 9, 614-619.

Herrera, M.B., Bussolati, B., Bruno, S., Morando, L., MaurielloRomanazzi, G., Sanavio, F., Stamenkovic, I., Biancone, L., and Camussi, G. (2007). Exogenous mesenchymal stem cells localize to the kidney by means of CD44 following acute tubular injury. Kidney Int. 72, 430-441.

Hertig, A., Verine, J., Mougenot, B., Jouanneau, C., Ouali, N., Sebe, P., Glotz, D., Ancel, P.Y., Rondeau, E., and Xu-Dubois, Y.C. (2006). Risk factors for early epithelial to mesenchymal transition in renal grafts. Am. J. Transplant. 6, 2937-2946.

Imberti, B., Morigi, M., Tomasoni, S., Rota, C., Corna, D., Longaretti, L., Rottoli, D., Valsecchi, F., Benigni, A., Wang, J., Abbate, M., Zoja, C., and Remuzzi, G. (2007). Insulin-like growth factor-1 sustains stem cell mediated renal repair. J. Am. Soc. Nephrol. 18, 2921-2928.

Kakoki, M., McGarrah, R.W., Kim, H.S., and Smithies, O. (2007). Bradykinin B1 and B2 receptors both have protective roles in renal ischemia/reperfusion injury. Proc. Natl. Acad. Sci. U.S.A. 104, 7576-7581.

Kanellis, J., Fraser, S., Katerelos, M., and Power, D.A. (2000a). Vascular endothelial growth factor is a survival factor for renal tubular epithelial cells. Am. J. Physiol. Renal Physiol. 278, F905-F915.

Kanellis, J., Mudge, S.J., Fraser, S., Katerelos, M., and Power, D.A. (2000b). Redistribution of cytoplasmic VEGF to the basolateral aspect of renal tubular cells in ischemia-reperfusion injury. Kidney Int. 57, 2445-2456.

Kelly, K.J., Williams, W.W., Jr., Colvin, R.B., Meehan, S.M., Springer, T.A., Gutierrez-Ramos, J.C., and Bonventre, J.V. (1996). Intercellular adhesion molecule-1-deficient mice are protected against ischemic renal injury. J. Clin. Invest. 97, 1056-1063. 
Kuldo, J.M., Westra, J., Asgeirsdottir, S.A., Kok, R.J., Oosterhuis, K., Rots, M.G., Schouten, J.P., Limburg, P.C., and Molema, G. (2005). Differential effects of NF- $\kappa$ B and p38 MAPK inhibitors and combinations thereof on TNF- $\alpha$ - and IL- $1 \beta$-induced proinflammatory status of endothelial cells in vitro. Am. J. Physiol. Cell Physiol. 289, C1229-C1239.

Lange, C., Togel, F., Ittrich, H., Clayton, F., Nolte-Ernsting, C., Zander, A.R., and Westenfelder, C. (2005). Administered mesenchymal stem cells enhance recovery from ischemia/reperfusion-induced acute renal failure in rats. Kidney Int. 68, $1613-1617$.

Li, H.J., Yin, H., Yao, Y.Y., Shen, B., Bader, M., Chao, L., and Chao, J. (2007). Tissue kallikrein protects against pressure overload-induced cardiac hypertrophy through kinin B2 receptor and glycogen synthase kinase- $3 \beta$ activation. Cardiovasc. Res. 73, 130-142.

Lieberthal, W. (1998). Biology of ischemic and toxic renal tubular cell injury: Role of nitric oxide and the inflammatory response. Curr. Opin. Nephrol. Hypertens. 7, 289-295.

Lim, S.Y., Kim, Y.S., Ahn, Y., Jeong, M.H., Hong, M.H., Joo, S.Y., Nam, K.I., Cho, J.G., Kang, P.M., and Park, J.C. (2006). The effects of mesenchymal stem cells transduced with Akt in a porcine myocardial infarction model. Cardiovasc. Res. 70, 530-542.

Mangi, A.A., Noiseux, N., Kong, D., He, H., Rezvani, M., Ingwall, J.S., and Dzau, V.J. (2003). Mesenchymal stem cells modified with Akt prevent remodeling and restore performance of infarcted hearts. Nat. Med. 9, 1195-1201.

Murakami, H., Yayama, K., Chao, L., and Chao, J. (1998). Human kallikrein gene delivery protects against gentamycin-induced nephrotoxicity in rats. Kidney Int. 53, 1305-1313.

Noiseux, N., Gnecchi, M., Lopez-Ilasaca, M., Zhang, L., Solomon, S.D., Deb, A., Dzau, V.J., and Pratt, R.E. (2006). Mesenchymal stem cells overexpressing Akt dramatically repair infarcted myocardium and improve cardiac function despite infrequent cellular fusion or differentiation. Mol. Ther. 14, 840-850.

Peresleni, T., Noiri, E., Bahou, W.F., and Goligorsky, M.S. (1996). Antisense oligodeoxynucleotides to inducible NO synthase rescue epithelial cells from oxidative stress injury. Am. J. Physiol. 270, F971-F977.

Prodjosudjadi, W., Gerritsma, J.S., Klar-Mohamad, N., Gerritsen, A.F., Bruijn, J.A., Daha, M.R., and van Es, L.A. (1995). Production and cytokine-mediated regulation of monocyte chemoattractant protein-1 by human proximal tubular epithelial cells. Kidney Int. 48, 1477-1486.

Schlondorff, D. (1995). The role of chemokines in the initiation and progression of renal disease. Kidney Int. Suppl. 49, S44-S47.

Spiecker, M., Darius, H., Kaboth, K., Hubner, F., and Liao, J.K. (1998). Differential regulation of endothelial cell adhesion molecule expression by nitric oxide donors and antioxidants. J. Leukoc. Biol. 63, 732-739.

Suzuki, K., Ota, H., Sasagawa, S., Sakatani, T., and Fujikura, T. (1983). Assay method for myeloperoxidase in human polymorphonuclear leukocytes. Anal. Biochem. 132, 345-352.
Tang, Y.L., Tang, Y., Zhang, Y.C., Qian, K., Shen, L., and Phillips, M.I. (2005). Improved graft mesenchymal stem cell survival in ischemic heart with a hypoxia-regulated heme oxygenase1 vector. J. Am. Coll. Cardiol. 46, 1339-1350.

Thurman, J.M. (2007). Triggers of inflammation after renal ischemia/reperfusion. Clin. Immunol. 123, 7-13.

Togel, F., Hu, Z., Weiss, K., Isaac, J., Lange, C., and Westenfelder, C. (2005). Administered mesenchymal stem cells protect against ischemic acute renal failure through differentiationindependent mechanisms. Am. J. Physiol. Renal Physiol. 289, F31-F42.

Togel, F., Weiss, K., Yang, Y., Hu, Z., Zhang, P., and Westenfelder, C. (2007). Vasculotropic, paracrine actions of infused mesenchymal stem cells are important to the recovery from acute kidney injury. Am. J. Physiol. Renal Physiol. 292, F1626-F1635.

Vinas, J.L., Hotter, G., Pi, F., Palacios, L., and Sola, A. (2007). Role of peroxynitrite on cytoskeleton alterations and apoptosis in renal ischemia-reperfusion. Am. J. Physiol. Renal Physiol. 292, F1673-F1680.

Xia, C.F., Yin, H., Borlongan, C.V., Chao, L., and Chao, J. (2004). Kallikrein gene transfer protects against ischemic stroke by promoting glial cell migration and inhibiting apoptosis. Hypertension 43, 452-459.

Yao, Y.Y., Yin, H., Shen, B., Chao, L., and Chao, J. (2007). Tissue kallikrein and kinin infusion rescues failing myocardium after myocardial infarction. J. Card. Fail. 13, 588-596.

Yin, H., Chao, L., and Chao, J. (2005). Kallikrein/kinin protects against myocardial apoptosis after ischemia/reperfusion via Akt-glycogen synthase kinase-3 and Akt-Bad.14-3-3 signaling pathways. J. Biol. Chem. 280, 8022-8030.

Yokoo, T., Sakurai, K., Ohashi, T., and Kawamura, T. (2003). Stem cell gene therapy for chronic renal failure. Curr. Gene Ther. 3, 387-394.

Zeiher, A.M., Fisslthaler, B., Schray-Utz, B., and Busse, R. (1995). Nitric oxide modulates the expression of monocyte chemoattractant protein 1 in cultured human endothelial cells. Circ. Res. 76, 980-986.

Zhang, J.J., Bledsoe, G., Kato, K., Chao, L., and Chao, J. (2004). Tissue kallikrein attenuates salt-induced renal fibrosis by inhibition of oxidative stress. Kidney Int. 66, 722-732.

$$
\begin{array}{r}
\text { Address reprint requests to: } \\
\text { Dr. Julie Chao } \\
\text { Department of Biochemistry and Molecular Biology } \\
\text { Medical University of South Carolina } \\
173 \text { Ashley Avenue } \\
\text { Charleston, SC } 29425
\end{array}
$$

E-mail: chaoj@musc.edu

Received for publication February 7, 2008; accepted after revision June 8, 2008.

Published online: July 16, 2008. 